\title{
El Boletín de Turismo Social de la Provincia de Buenos Aires
}

\section{The Social Tourism Bulletin of the Province of Buenos Aires}

Imágenes y texto: Claudio Panella

permarieze@hotmail.com

https://orcid.org/oooo-ooo1-9475-8661

\section{Peronismo y turismo social}

Durante los años del primer peronismo, el pleno empleo, los elevados salarios que percibían los trabajadores y una legislación social de avanzada - que contempló, entre otras leyes, las de vacaciones pagas y el sueldo anual complementario (aguinaldo)—, permitieron pensar en la planificación del descanso y en el disfrute del «veraneo» por parte del obrero y su familia, además de los sectores medios, que en parte ya gozaban de aquellos beneficios. La cuestión del tiempo libre y del ocio popular tuvieron un lugar destacado en las políticas estatales de aquel gobierno, en un escenario social definido como de «democratización del bienestar», que se manifestó en un crecimiento del consumo de entretenimientos populares, entre ellos la asistencia a salas de cines, los espectáculos deportivos y el desarrollo del turismo social (Torre \& Pastoriza, 2002).

De esta manera, el programa del ocio peronista, si bien consolidó líneas ya iniciadas en los años treinta, puso en marcha el diseño de un proyecto de turismo social asentado en la concepción de las vacaciones como una conquista simbólica asociada al Derecho al Descanso del trabajador (Pastoriza, 2011). El Estado nacional -a través del ministerio de 
Obras Públicas-, los Estados provinciales, la Fundación Eva Perón y las organizaciones sindicales fueron los canales a través de los cuales se implementó este singular plan turístico popular, que tuvo entre sus principales destinos la ciudad de Mar del Plata, en la costa atlántica bonaerense, y las sierras de la provincia de Córdoba, pero también las Cataratas del Iguazú, el lago Nahuel Huapi y las estaciones termales de Mendoza.

La provincia de Buenos Aires, gobernada por el Cnel. Domingo A. Mercante (1946-1952), fue la primera en ensayar planes sociales turísticos, entendidos como la conquista de un derecho cívico, de allí la sanción, en 1948, de la ley provincial 5.254 que creó la Dirección de Turismo y Parques, que tendría su cargo todo lo referente al desenvolvimiento del turismo provincial. Esta oficina tenía por finalidad la coordinación que en esta materia desarrollaban el Estado y las instituciones privadas de acuerdo a los siguientes fines: conservar y proteger las zonas y los lugares turísticos, y las bellezas naturales; impedir la destrucción o el deterioro de monumentos o de lugares históricos proveyendo su conservación; celebrar convenios con el Estado Nacional, con los Estados provinciales y con los municipios que fomenten la actividad turística; crear y habilitar lugares de descanso e instalar construcciones en las playas públicas destinadas a facilitar su uso sin cargo alguno; impulsar el turismo social, a fin de facilitar el descanso al mayor número de personas, mediante campamentos económicos y colectivos; proteger al turista (Ley provincial 5.254, 1948).

Bajo el imperio de la consigna «Usted paga el viaje, la provincia el hospedaje», el gobierno bonaerense llevó a cabo el citado Plan de Turismo Social, cuyas iniciativas más significativas se materializaron en distintos planes, como los que se detallan a continuación:

- Turismo provincial de verano: eran vacaciones de diez días, entre los meses de diciembre y de abril, en los que el Estado bonaerense proporcionaba hospedaje gratuito en los centros turísticos de Mar del Plata, Necochea, Sierra de la Ventana, Carhué y Tandil.

- Turismo interprovincial de invierno: se realizaba entre los meses de julio y de octubre durante la misma cantidad de días en las provincias de Mendoza, Catamarca, San Luis, Santiago del Estero y Córdoba.

- Vacaciones económicas: comprendían nueve días en cualquier balneario bonaerense seleccionado por sorteo. 
- Excursiones Sanmartinianas: se organizaban en ómnibus a lugares históricos vinculados al Libertador (Yapeyú, San Lorenzo y Mendoza).

- Excursiones justicialistas: se trataba de viajes que recorrían las distintas obras gubernativas, como el complejo recreativo de Ezeiza y el aeropuerto «Ministro Pistarini», el Parque «Los Derechos de la Ancianidad» (Pereyra Iraola), la República de los Niños (La Plata), Ciudad Evita (La Matanza), el Barrio «Los Perales», la sede de la Fundación Eva Perón y la Ciudad Infantil (todos en la Capital Federal).

- Excursiones fluviales: recorrían desde el puerto de La Plata hasta el de Asunción por el río Paraná mediante el vapor «Justicia Social».

- Viaje de Bodas: consistía en un viaje para las parejas recién casadas de una semana con pensión completa - sin pasaje- en un hotel de las ciudades de Mar del Plata, Buenos Aires, Tandil, Chascomús, Sierra de la Ventana, Monte Hermoso, Mar de Ajó, Necochea, Bahía Blanca y Carhué (Pastoriza, 2005, pp. 308-309).

\section{El Boletín de Turismo Social}

Con el fin de difundir la obra social y de turismo que llevaba a cabo el gobierno del Cnel. Mercante a través de la Dirección de Turismo y Parques, cuyo titular era Julio A. Tavella, en la segunda mitad de 1951 se comenzó a publicar el Boletín de Turismo Social de la Provincia de Buenos Aires (en adelante BTS), revista auspiciada por el gobierno provincial a través del decreto 15.474 del 31 de julio de ese año. Se especificaba en el mismo que todo el material informativo que demandase la publicación sería facilitado por el Departamento de Prensa y Publicaciones del Ministerio de Hacienda, Economía y Previsión, y por la Dirección de Turismo y Parques.

Se contemplaba una tirada de 10.000 ejemplares por número, la mitad de los cuales se debía entregar sin cargo a la Dirección de Turismo y Parques para su distribución en sindicatos, bibliotecas públicas, escuelas, embajadas y consulados del país en el exterior como medio de difusión internacional de la obra realizada. La otra mitad debía ser distribuida, con carácter gratuito, entre los anunciantes del BTS, las industrias y los municipios de la provincia. La financiación de la publicación sería a través de la publicidad 
que se obtendría del comercio y la industria interesados en efectuarlas. Finalmente, se autorizaba a establecer como Dirección postal de la publicación el domicilio de la Casa de la Provincia de Buenos Aires en la Capital Federal (Av. Callao N. ${ }^{\circ}$ 237) [Decreto provincial 15.474, 1951].

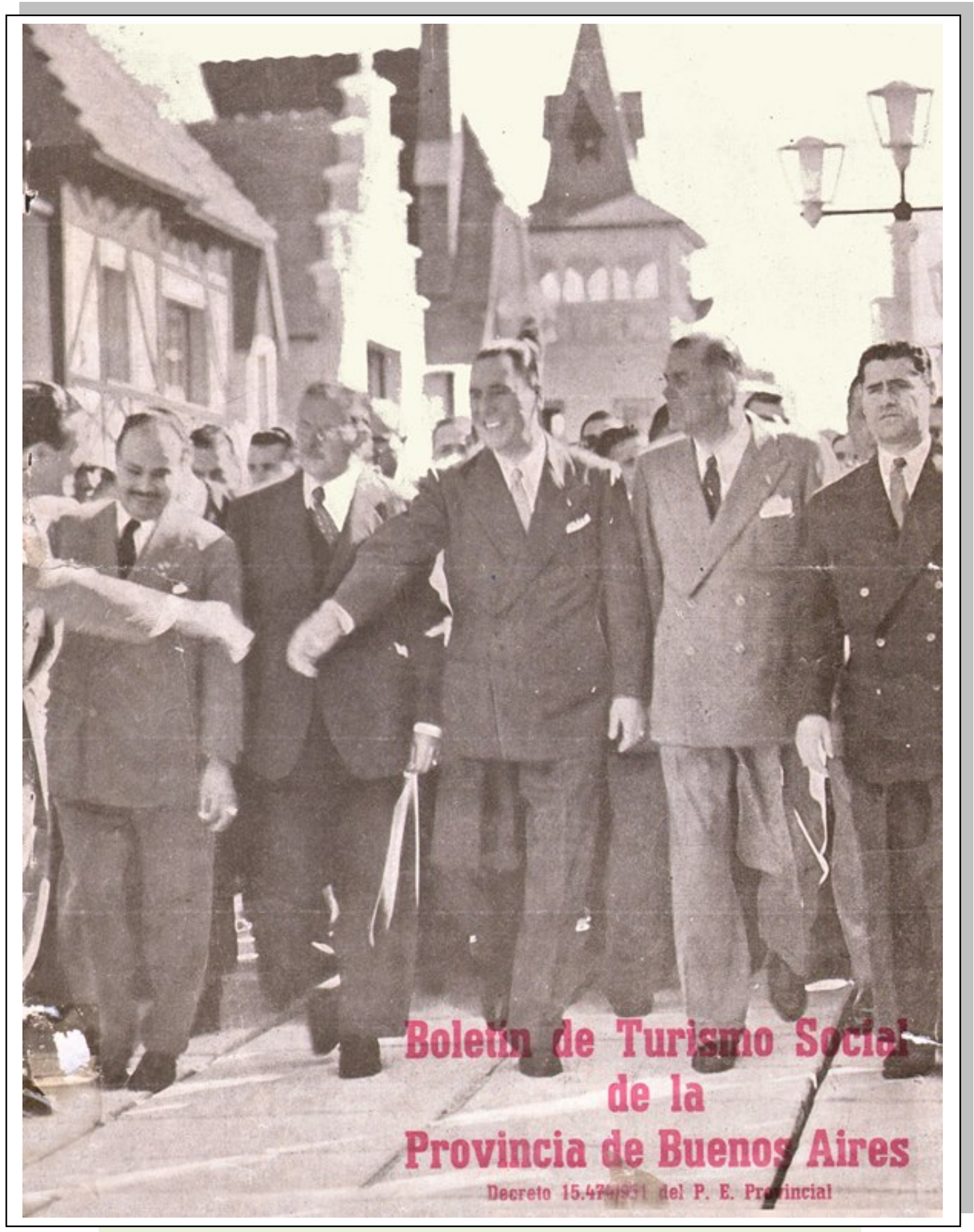

Inauguración de la República de los Niños

(Portada de Boletín de Turismo Social, núm. 2, enero de 1952) 
Los directores del BTS eran Jorge E. Freeland, Norberto García y Alberto F. Vilabrille. La publicación, que contaba con entre 100 y 150 páginas, era promocionada como la «primera y única especializada en su género» existente en el país. Se editaron tres números, el primero a fines de 1951 y los restantes en enero y en mayo de 1952, que brindaban generosa información sobre destinos turísticos y sobre labor de la Dirección.

Con una amplia cobertura fotográfica y un lenguaje comprensible para todo público, se explicaban las bondades de cada lugar o ciudad turística, sus bellezas y los servicios para el visitante. De este modo, el BTS consignaba que la provincia contaba con todas las atracciones naturales: mar, ríos, lagunas, sierras, termas y sitios histórico culturales, que se podían practicar todos los deportes: natación, pesca, caza, equitación, remo, automovilismo, ciclismo, andinismo; y que se ofrecía acceso a los centros turísticos a partir de las redes ferroviaria y caminera, y numerosos hoteles y hosterías (BTS, núm. 2 , enero de 1952, p. 153).

El destino turístico más importante y popular era Mar del Plata, que desde los años treinta, pero sobre todo desde la llegada del peronismo, se había vuelto un lugar de descanso masivo; efectivamente, en 1930 fue visitada por 6o.ooo personas, que llegaron a 380.000 una década más tarde, a 1.000.000 en 1950 y a 1.400.00o en 1955 . Un censo hotelero relevado por la Dirección de Turismo, en 1951, confirmó esta supremacía: de un total de 1.437 hoteles con 28.497 habitaciones en la Provincia, 921 y 19.782, es decir $64 \%$ y 69,4\%, respectivamente, le correspondían a la «Ciudad Feliz». El segundo destino turístico en importancia era Necochea, con 107 hoteles y 2.432 habitaciones, y el tercero Tandil, con 94 y 1.365 respectivamente (BTS, núm. 2, enero de 1952, p. 78).

Los demás balnearios también eran publicitados, con títulos que anunciaban sus principales atractivos: «Necochea, segunda perla del Atlántico»; «San Clemente del Tuyú, con amplias playas y pintorescas rías internas, brinda al turista pasos y comodidades»; «Tres balnearios que prosperan: Mar del Tuyú, La Lucila y Costa Azul»; «Santa Teresita, balneario juvenil y progresista, tiene un gran muelle para la pesca deportiva»; «San Bernardo impresiona por la belleza de sus construcciones y sus jardines»; «Mar de Ajó es uno de los balnearios de más potentes sugestiones para el turista»; «Pinamar, un jardín ondulante frente al océano, tiene ahora la ventaja del ferrocarril»; «Villa Gesell es el resultado de una paciente obra de forestación»; «Miramar, lugar ideal para el descanso integral en playa marina»; «Monte Hermoso, nuevo balneario de amplias playas»; «Un balneario que se libró al público después que se habían arbolado los médanos: Pehuen-có». 


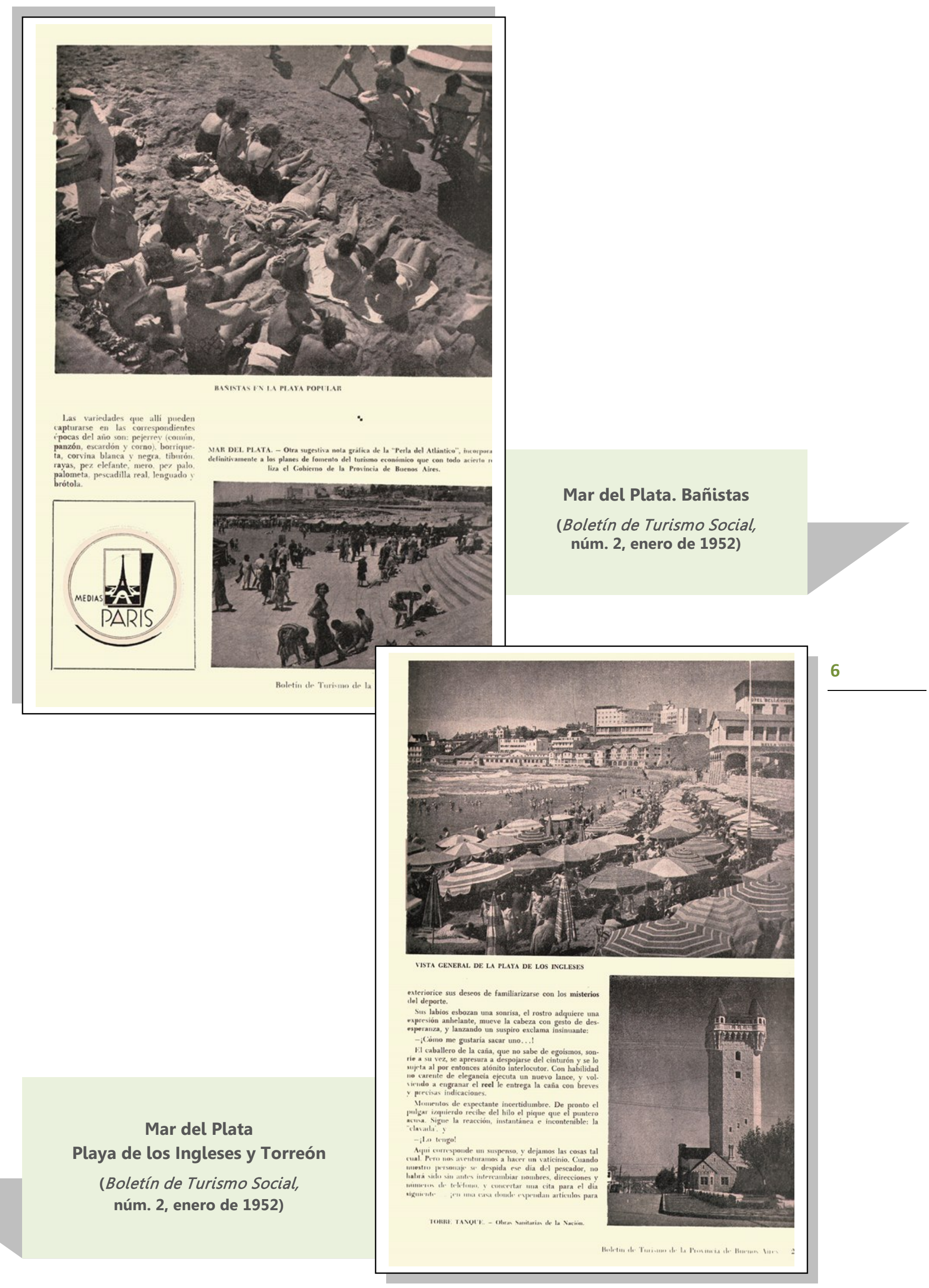




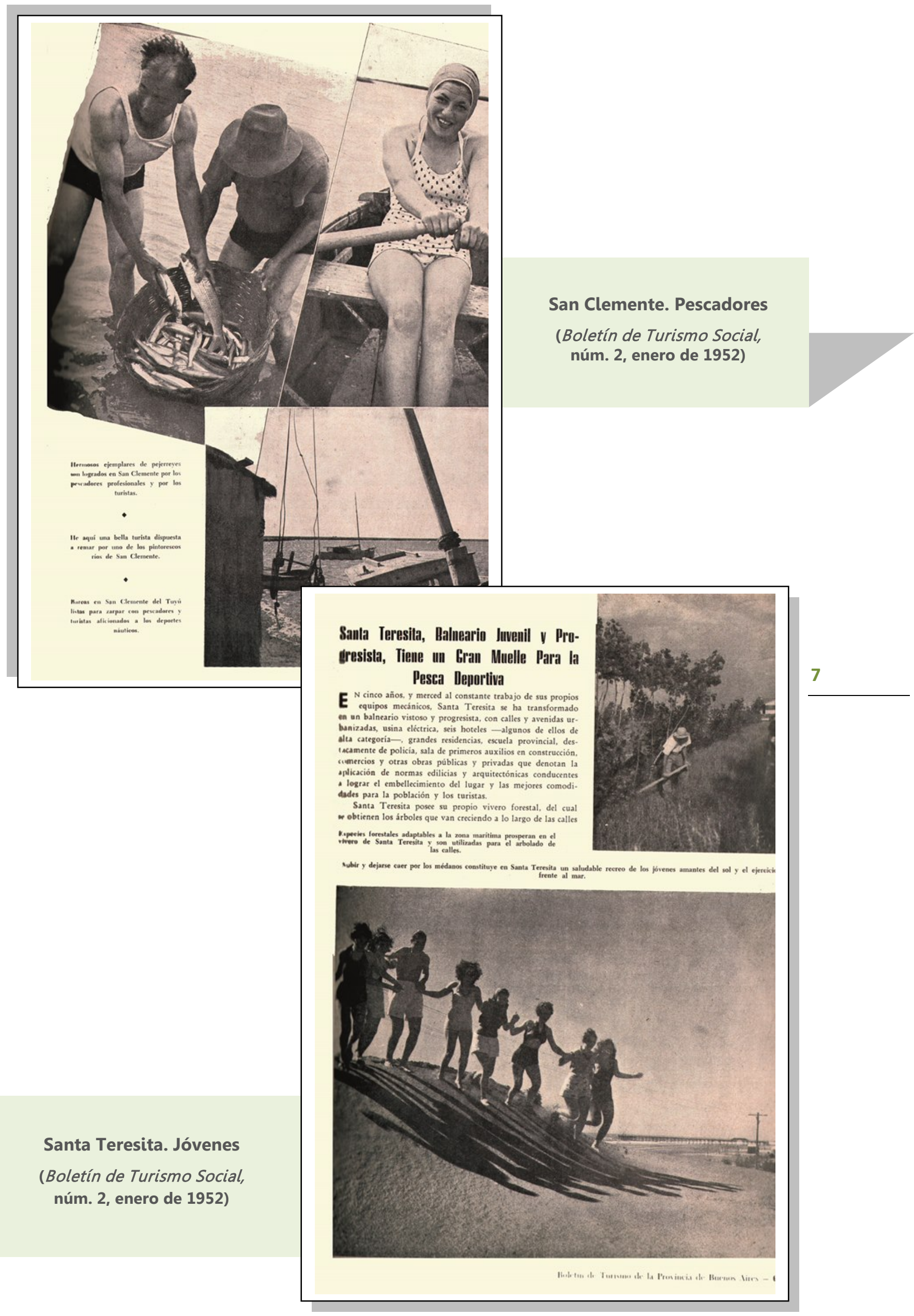


Además de las ciudades balnearias, tenían cabida en el BTS notas sobre otros atractivos turísticos naturales bonaerenses, como las lagunas y las sierras. Así, se mostraba la laguna de Puan, de reducida profundidad y una superficie de 500 hectáreas; la de Chasicó, que tiene la particularidad de encontrarse bajo el nivel del mar; el lago Epecuén, de aguas saladas y termales; y la laguna de Chascomús. Esta última se promocionaba a partir de estar situada relativamente cerca de Buenos Aires -a 123 kilómetros- y de ofrecer «al turista más exigente», las más amplias posibilidades de recreo y de descanso. Expresaba que los aficionados a la pesca, a la natación, al remo y a la navegación podían encontrar en aquella «las más grandes facilidades para su práctica» y contar con espacios para su esparcimiento y su comodidad (BTS, núm. 2, enero de 1952, p. 117).

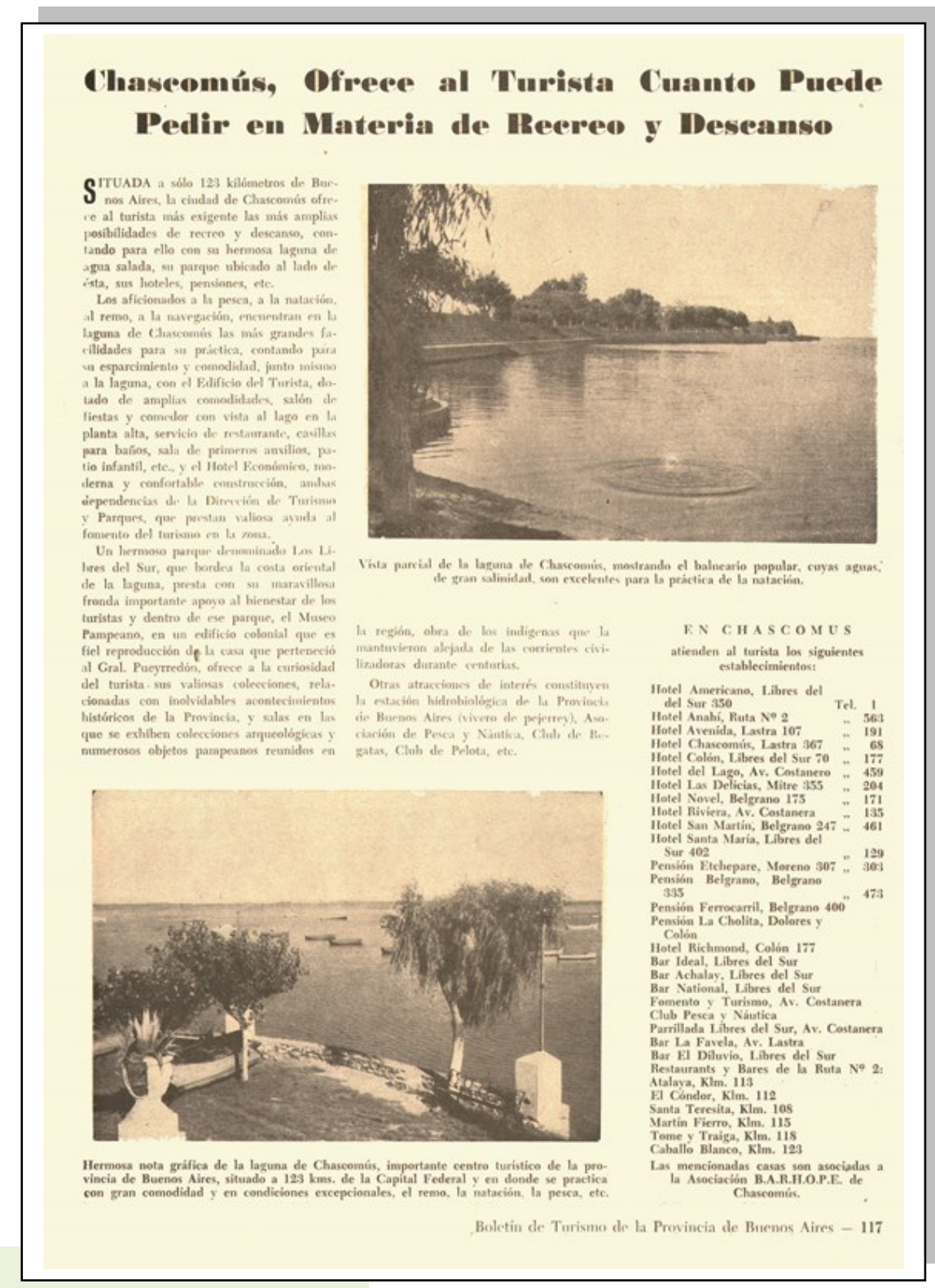

Laguna de Chascomús

(Boletín de Turismo Social,

núm. 2, enero de 1952) 
Las serranías también tenían su espacio en el BTS, como los parajes de Tornquist, de Saldungaray y de Sierra de la Ventana, donde era cada vez mayor el número de personas que acudían allí «para gozar de maravillosos paisajes naturales en los que la acción del hombre, todavía, no ha cambiado la faz de la naturaleza» (BTS, núm. 3, mayo de 1952, p. 51). No descuidaba la publicación otras plazas turísticas como la del delta del Tigre; de hecho, en esta ciudad, y atento al desarrollo que había adquirido la región, la Dirección de Turismo y Parques abrió una Oficina de Informes y Delegación (BTS, núm. 2, enero de 1952, p. 105).

Otra modalidad de difusión que tuvo el BTS, en especial para ciudades que no integraban las principales recorridos turísticos, fue el de encontrarles algún atractivo a partir de su propio devenir histórico. De este modo, Carmen de Patagones era «la única población sureña cuyo origen se remonta a la época española»y Pigüé era el lugar en donde «se reunió la primera conscripción argentina» (BTS, núm. 2, enero de 1952, p. 134 y 137).

Ampliamente publicitado en el BTS era el Plan Viaje de Bodas, que se mostraba como un derecho que poseían las jóvenes parejas que se unían en matrimonio, una necesidad para aquellos que proyectaban la vida en común con el objeto de conformar una familia. De allí que ese viaje no era «algo arbitrario o un gasto inútil, sino la expansión necesaria para que tanto el hombre como la mujer, cuando tengan que retomar el hilo cotidiano de sus tareas, puedan afrontarlas con el rostro sonriente y con el optimismo lógico de quien tiene fe en la vida y en el porvenir» (BTS, núm. 3, mayo de 1952, p. 26).

Viaje de Bodas

(Boletín de Turismo Social, núm. 2, enero de 1952)

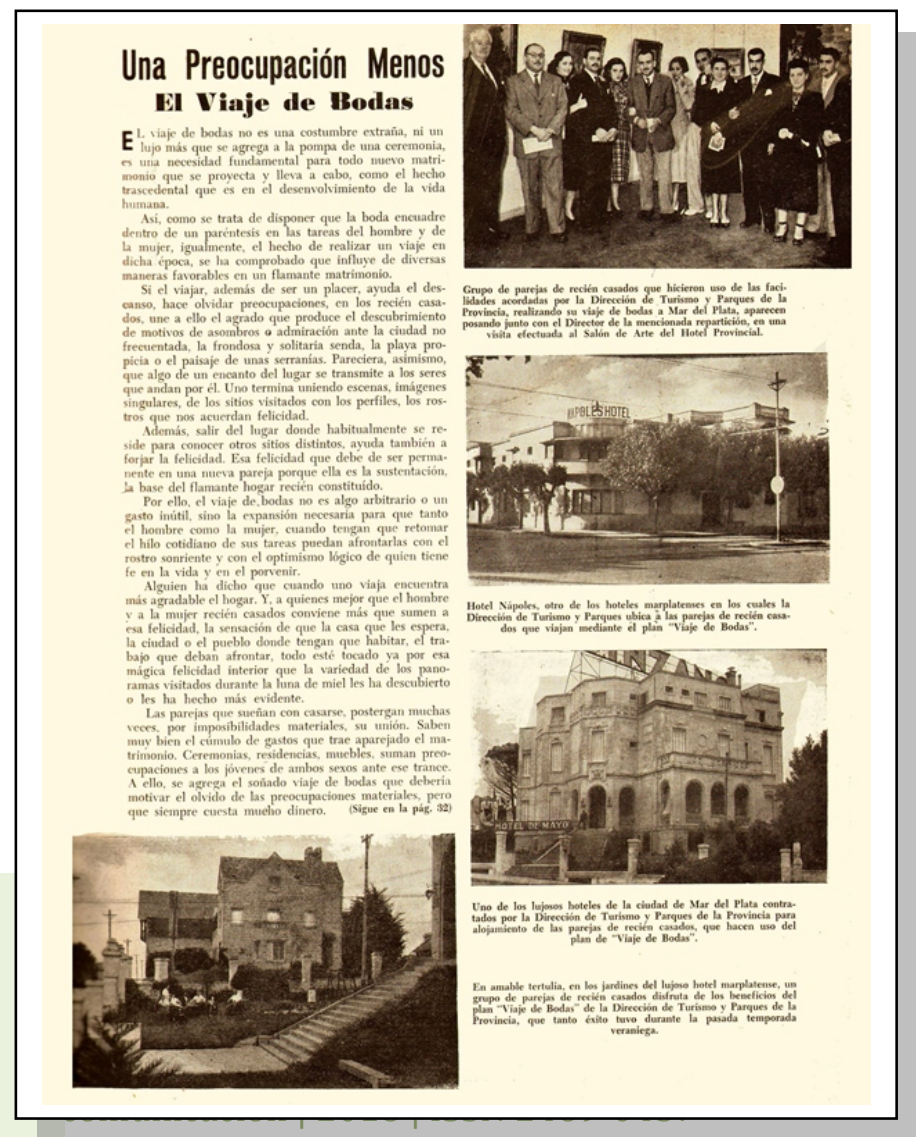


El BTS destacaba que en el transcurso de 1951 unas 46.ooo personas habían gozado de las «Excursiones Justicialistas», aunque hacía especial referencia a dos destinos que constituían obras realizadas por el gobierno provincial: la República de los Niños, levantada en la localidad de Gonnet, partido de La Plata, y el Parque «Los Derechos de la Ancianidad», en el actual partido de Berazategui. La inauguración de la República, el 26 de noviembre de 1951, tuvo una amplia cobertura del BTS, que destacó no solo la presencia del Presidente Juan Domingo Perón sino también sus instalaciones y el sentido que tenía, pues serviría de «campo de experimentación para el desarrollo integral de la infancia para la formación del ciudadano de la Nueva Argentina, ejemplarmente dotado en el orden moral y físico para la función pública» (BTS, núm. 2, enero de 1952, p. 6).

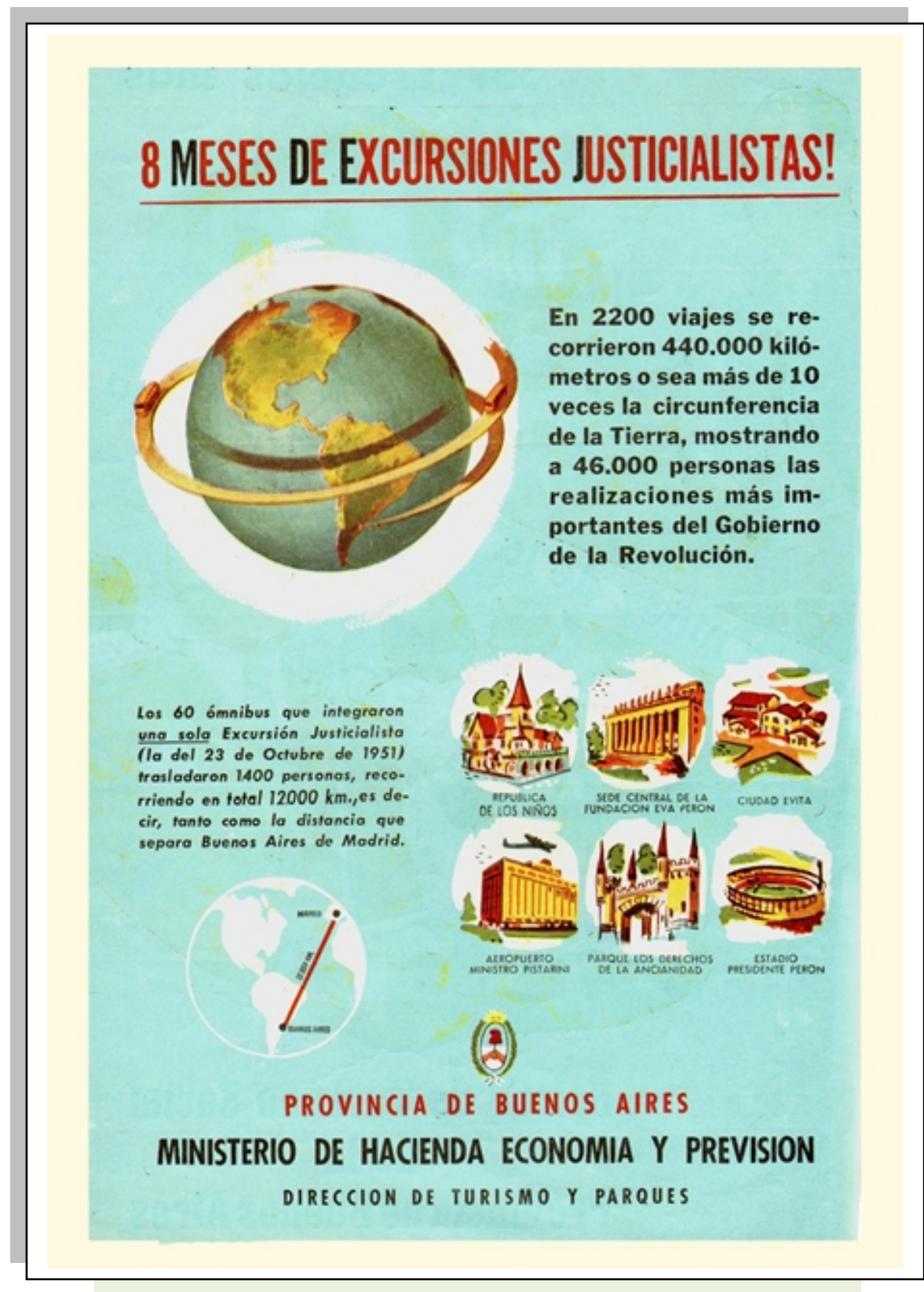


El parque «Los Derechos de la Ancianidad», inaugurado el 24 de febrero de 1950 a partir de terrenos expropiados a la familia Pereyra Iraola, era promocionado por el BTS como un lugar de descanso, de alegría y de sano esparcimiento para las familias trabajadoras en contacto con la naturaleza y el aire puro. Aunque no se dejaba de mencionar que, gracias a la acción del gobierno provincial, ese espacio verde «que otrora fue solaz y recreación de discutible señoría, ahora se encuentra al servicio de la comunidad» (BTS, núm. 2, enero de 1952, p. 149).

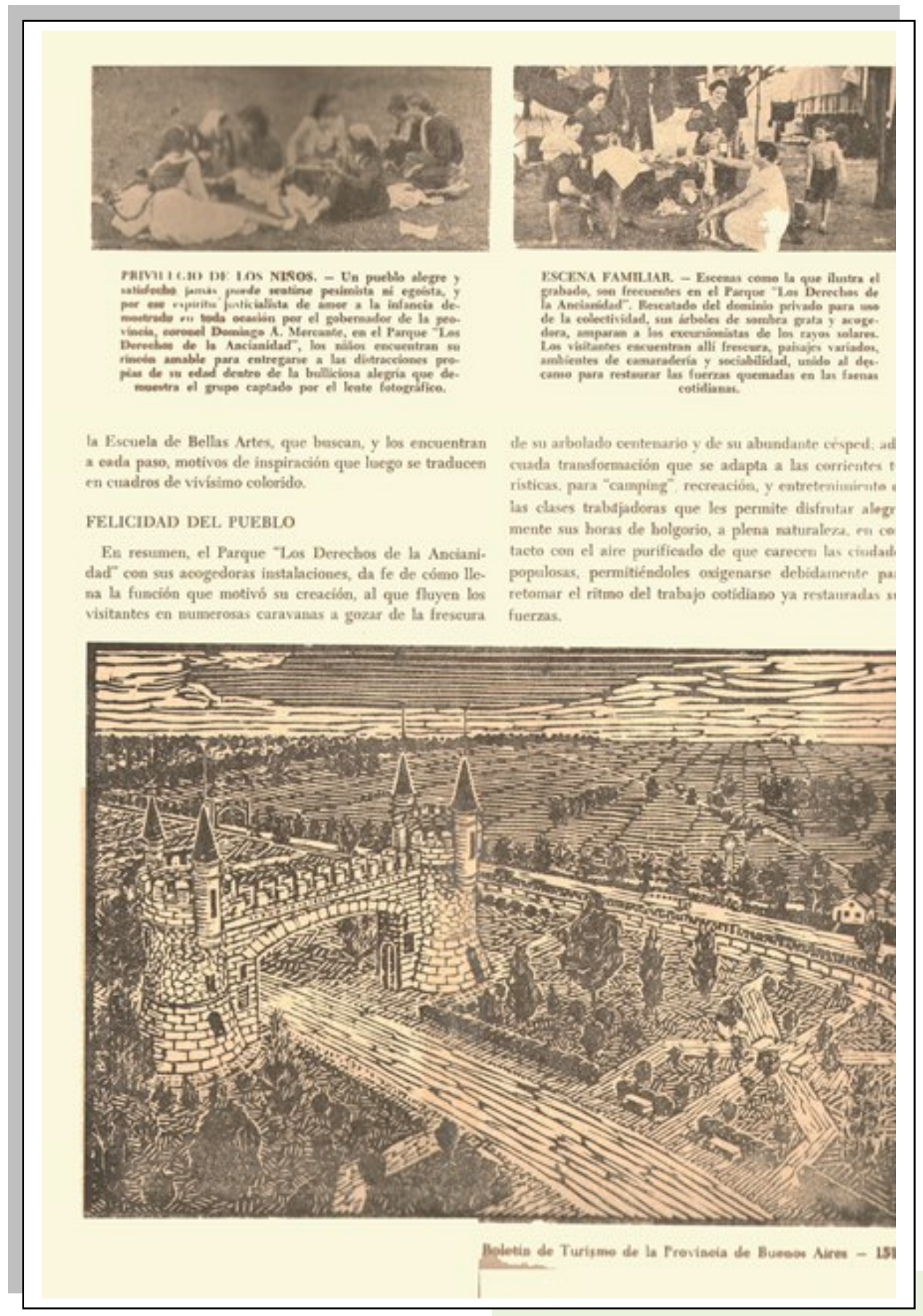


La Subsecretaría de Previsión —agencia de la que dependía la Dirección de Turismo y Parques-, a través de su titular, Francisco Capelli, suscribió convenios con sus similares de varias provincias que contemplaban el intercambio de contingentes de turistas «dentro de los principios del turismo social». En el caso de San Luis, se estableció que los puntanos visitasen Mar del Plata en verano y los bonaerenses las serranías sanluiseñas en otoño y en invierno. El BTS ofreció a sus lectores amplia información sobre los distintos lugares turísticos de la provincia cuyana, entre ellos la ciudad Capital, Potrero de los Funes y la Villa de Merlo (BTS, núm. 3, mayo de 1952, p. 55).

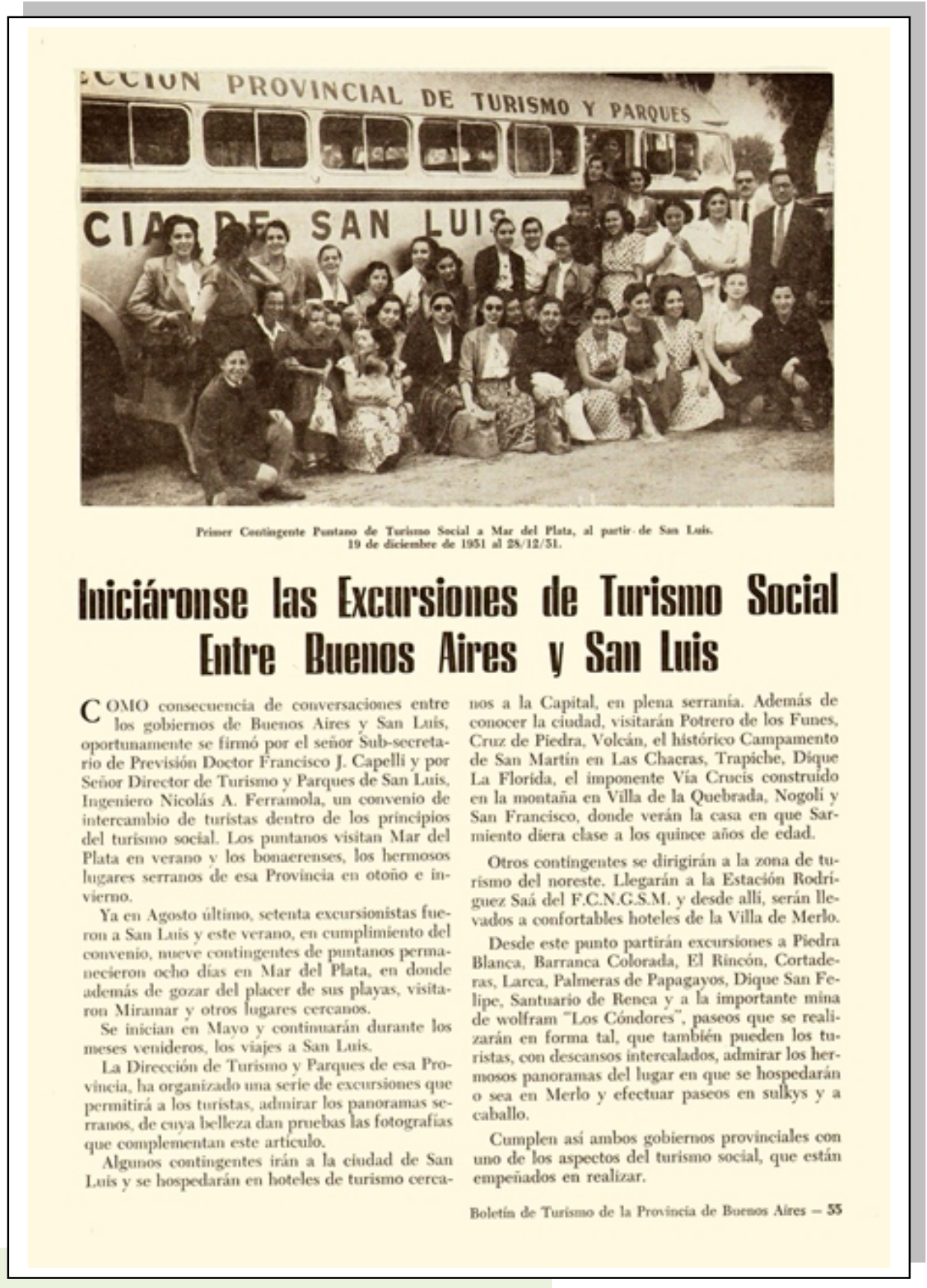

Turismo interprovincial, San Luis

(Boletín de Turismo Social, núm. 3, mayo de 1952) 
Lo que en la actualidad se denomina turismo cultural gozó de referencia concreta en el BTS. A través de la publicación, se invitaba a visitar los museos de este tipo sitos en la provincia: el de Historia Natural y el de Bellas Artes, ambos de La Plata; el Colonial e Histórico de Luján; el Gauchesco, de San Antonio de Areco; la Casa del Acuerdo, de San Nicolás; el Libres del Sur, de Dolores: el Bromatológico, de Necochea; el de Bellas Artes, de Tandil; el de la Conquista del Desierto, de Trenque Lauquen; y el Pampeano, de Chascomús.

Con relación al Museo de Historia Natural, dependiente de la Universidad Nacional de La Plata, luego de elogiar el edificio, el BTS destacaba tanto las distintas salas - la de Arqueología y Etnografía, la Peruana, la de Botánica, la de Zoología y la de Mineralogíacomo las diferentes colecciones que albergaba la institución — como la paleontológica-. El Museo ofrecía al público visitante «un amplio cuadro de la naturaleza, el más completo y vasto que pueda imaginarse», pues abarcaba «desde el origen de las formas vivas hasta la aparición del Hombre y el florecimiento de las grandes culturas americanas». Con ello se cerraba «ese gigantesco ciclo de la naturaleza» que inspirara al Perito Moreno, cuando al fundar el Museo «le dio la simbólica forma de un anillo biológico» que «comienza en el misterio y termina en el Hombre» (BTS, núm. 2, enero de 1952, p. 35).

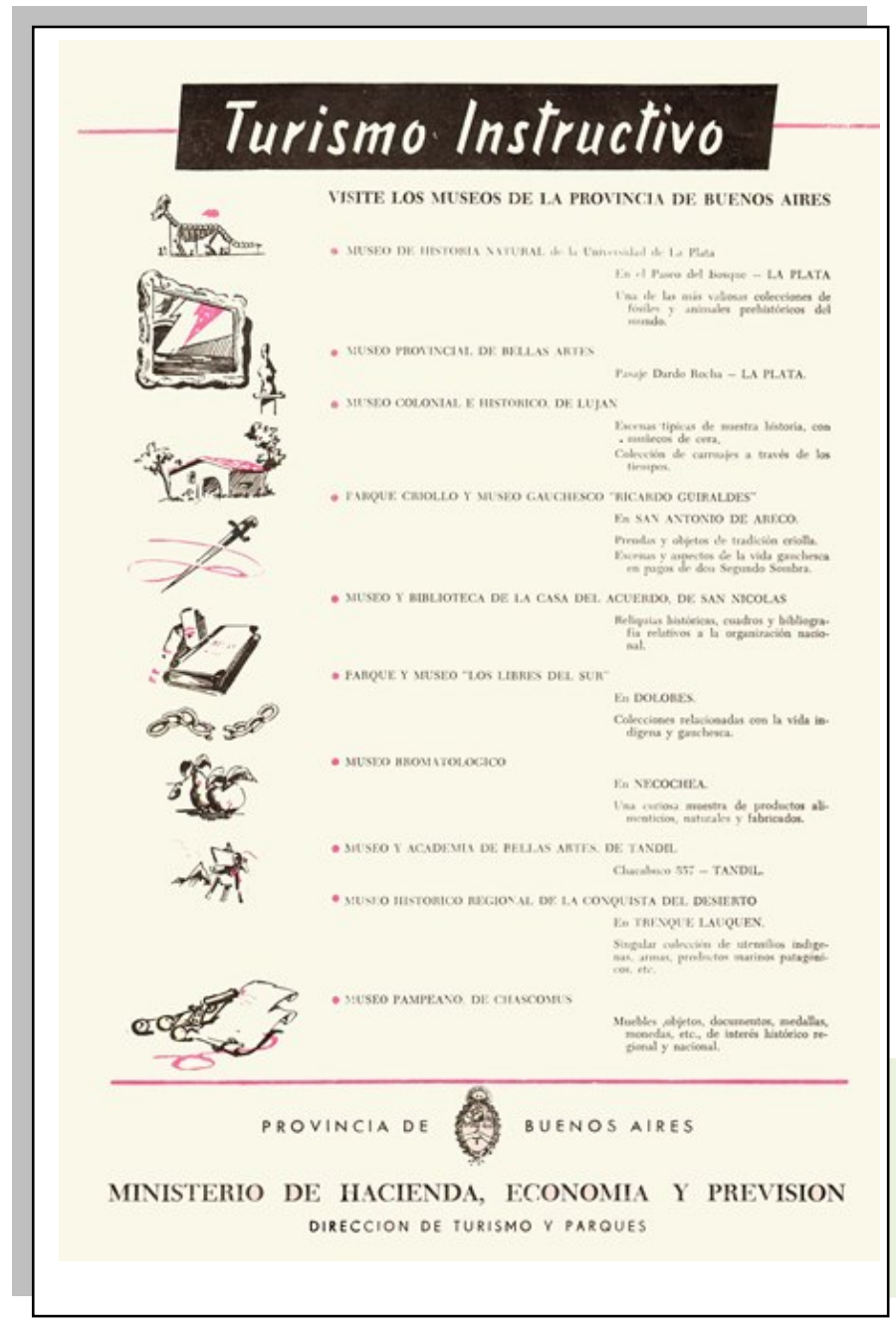




\section{EL MUSEO DE LA PLATA}

CENTRO DE CULTURA

CIENTIFICA al alCance

DE TODOS

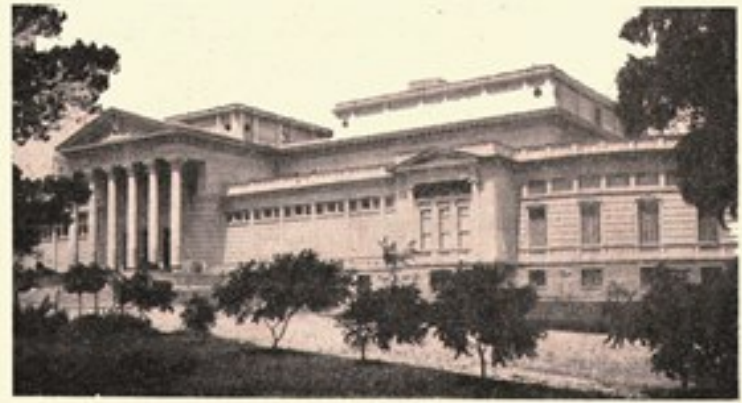

Muneo de la Mass. Freme priscipul

C unvoo pos primera vez se visita el Musco de La C Pata causa admiración y sorpresa al encoatrats

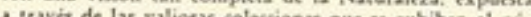
- teaver de las valiosos colectiones que se exhiben al púDende las azrentes vitrinsa

Desde las agrupaciones de seres inferiofes que tepre.

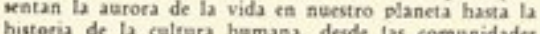
de pequefios organismos hasta las formas primitivas del de pequetios organismos hasea las formas primitivas de gineto Homo y los restos de las grasdes civilizaciones con todos intos motivos de curionidad papa et a europea. ran todos in los motivos de curicasdad para el turista que cusca en el Mucho de la plata no solo elevar su nivel Universo y de la vida que derde la aneigerdad has des

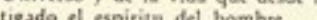
tigado el espirita dal hombre

menira conjesciba edicio det Museo ropresenta una atimponentes columass, varios eatilos. L. I fachada, con sus la areuitectura helinica ules del frente asi ceme les del vertibulo externamer totenda son americanos, los del vestibulo exterior y la

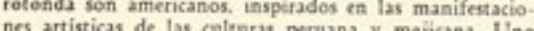
de los altes relieves del ferole cepresenta to Templo del Sel de Tiahuasuse. motivo que se ha mecoserifuido de

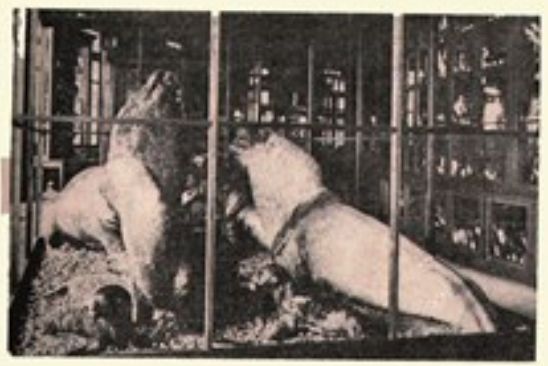

Lobs marina Otaria Flavescem. Bakia del Fooda, Tentionio de

maf́o natural en la Sala Perusos del piso alto

En homenaje a los gtandes nateralisas qee mis se hat distinguido por sus estudios telacionados con probsemas cientificos sudamericanos, por inikutiva del fundador primer director del Mnseo doctor Francisco P. Moreno fuezon colecados en lo alto de su frontispicio una serie de bustos que repecsentan a Bowchat de Pertes. Lamatek. Winckelmann, Blumenbach, Linne, Cuvier. Humboldt Azara. Darwin. D'Orbigny. Broxa y Brarard.

Las colecciones paleontologicas, que han dado exnom bre universal al Musto de La Plata. a tal punto que en

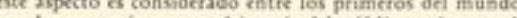
wen las que mas atraen el interés del público culto por la enajestuosedad y rafeza de sas foriles. Devie las formas redimentarias de organismos de la era primaria o pacoozosica, que solo ban dejado impresiones en las rocas. hasta los dinosaurios gigastescos del prriodo seranda. tio. sezuido por la aparición de los mamitetos que se expanden th forma prodigiou en of terciario paralelas. mente a ta extinción de los eeptiles y llegando a la ers culctartia catactetizada por la apurición del Hombre. todo es objeto de curiosidad frente al testimonio de cas raras apecies que ante poblaron naestras tietras y que se han extinguido por completo debido a factores com-
plejos que todavia la ciencia investiga. Entre ellas me-

Museo de Ciencias Naturales de La Plata

(Boletín de Turismo Social, núm. 2, enero de 1952)

El balance que hacía el BTS de la política turística del Cnel. Mercante era altamente positivo, resaltando la cantidad de personas que se habían beneficiado con ella, que cifraba en 192.597 beneficiarios durante 1951, a partir de una obra de gobierno que incorporaba nuevos bienes para el disfrute turístico «construyendo hoteles, adquiriendo elementos de movilidad y navegación y promoviendo en general la acción turística en todo el territorio provincial» (BTS, núm. 2, enero de 1952, p. 16). 
Con relación al costo que demandaba la publicación, se solventaba con el producido de la publicidad, que ocupaba más de $40 \%$ del total de las páginas de cada número. Los principales anunciantes eran los propietarios de hoteles, a los que se le sumaba todo tipo de comercios y de productos e, inclusive, de avisos clasificados.

El BTS tuvo una corta vida de tres números, como ya se adelantó; la causa fue el cambio de gobierno provincial, ejercido a partir de junio de 1952 por el Mayor Carlos Aloé. El nuevo mandatario dejó de auspiciar la publicación al derogar el decreto correspondiente a través del 4.718, del 18 de diciembre de 1952, con el argumento de evitar «toda confusión» que podía generar el hecho de que en el BTS no se aclaraba debidamente que se trababa de una publicación «no oficial».

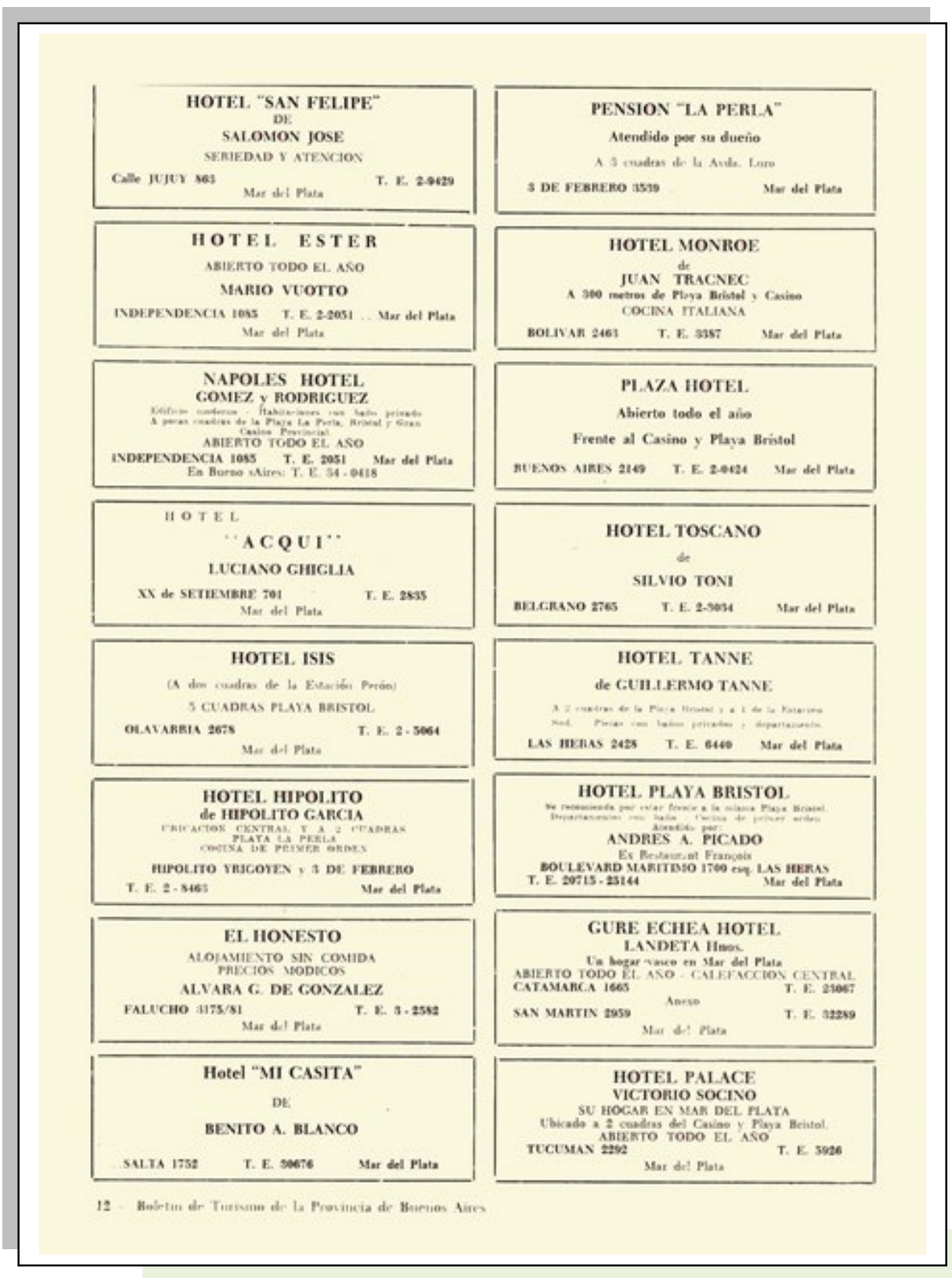




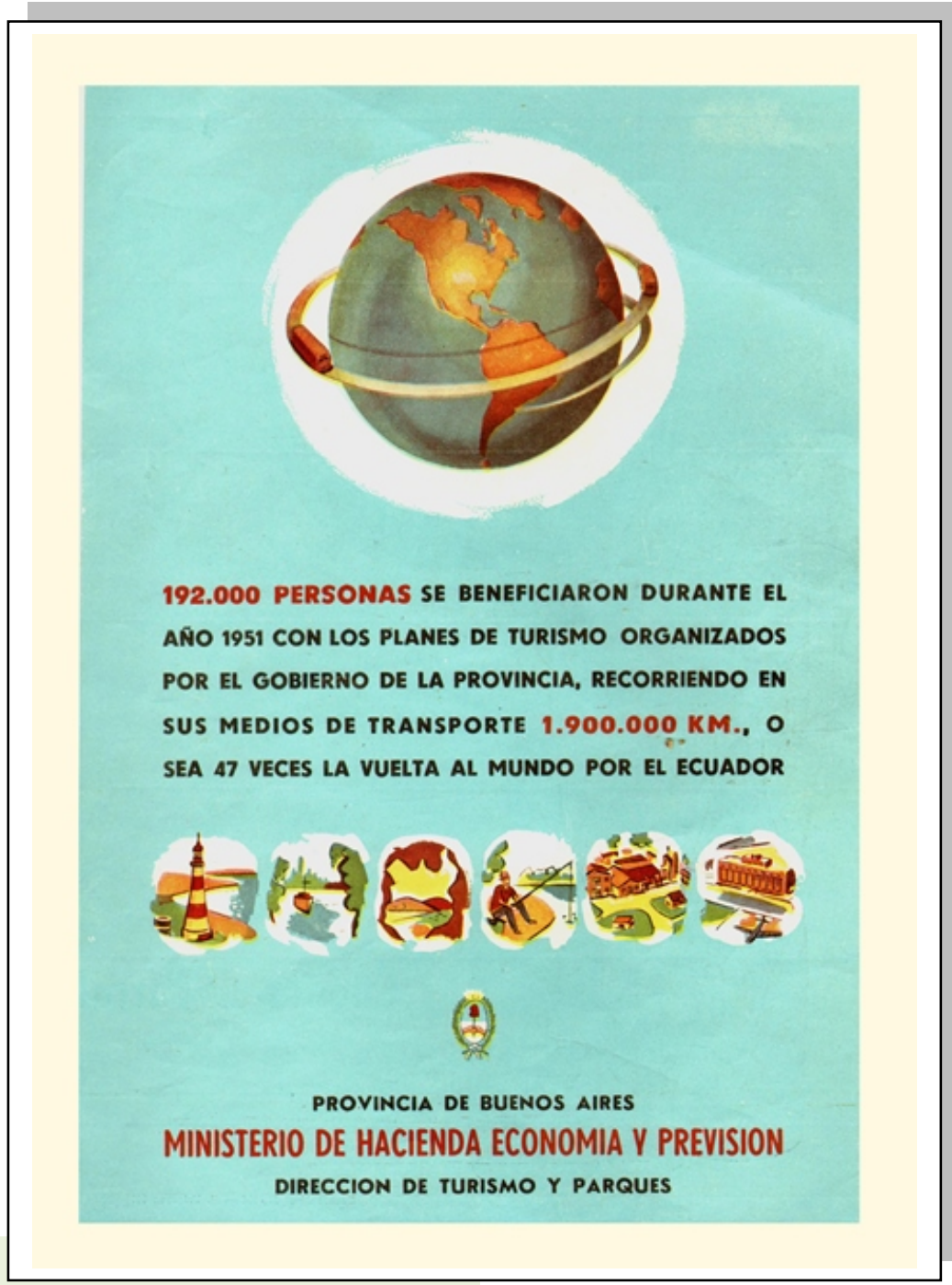

Turistas en 1951

(Boletín de Turismo Social, núm. 3, mayo de 1952)

\section{Referencias}

Pastoriza, E. (2005). «Usted paga el viaje, la provincia el hospedaje». Mar del Plata, el turismo social y las vacaciones populares durante el gobierno de Domingo Mercante. En C. Panella (Comp.), El gobierno de Domingo A. Mercante en Buenos Aires (1946-1952). Un caso de peronismo provincial (pp. 297-320). La Plata, Argentina: Instituto Cultural de la Provincia de Buenos Aires/Archivo Histórico Dr. Ricardo Levene.

Pastoriza, E. (2011). La conquista de las vacaciones. Breve historia del turismo en la Argentina. Ciudad Autónoma de Buenos Aires, Argentina: Edhasa. 
Provincia de Buenos Aires (Argentina). Decreto 15.474 (31 de julio de 1951).

Registro Oficial, 1951, vol. III, julio-septiembre, pp. 383-384. Eva Perón

(La Plata), Argentina: Dirección de Impresiones Oficiales.

Provincia de Buenos Aires (Argentina). Decreto 4.718 (18 de diciembre de 1952). Registro Oficial, 1952, vol. VII, diciembre, pp. 170-171. La Plata, Argentina: Dirección de Impresiones Oficiales.

Provincia de Buenos Aires (Argentina). Ley 5.254 (1948). Dirección de Turismo y Parques. Recuperado de http://www.gob.gba.gov.ar/intranet/digesto/PDF/15254.pdf

Torre, J. C. y Pastoriza, E. (2002). La democratización del bienestar. En J. C. Torre (Dir.), Nueva Historia Argentina VIII. Los años peronistas (1943-1955) [pp. 257-312]. Ciudad Autónoma de Buenos Aires, Argentina: Sudamericana.

\section{Fuentes analizadas}

Boletín de Turismo Social de la Provincia de Buenos Aires (enero de 1952). Núm. 2. Eva Perón (La Plata), Argentina: Dirección de Turismo y Parques.

Boletín de Turismo Social de la Provincia de Buenos Aires (mayo de 1952).

Núm. 3. Eva Perón (La Plata), Argentina: Dirección de Turismo y Parques. 